\title{
A Comparative analysis: Fertilizer and Pesticide Application Rates between China and Typical Developed Countries
}

\author{
Xiaoying $\mathrm{Ye}^{1, \mathrm{a}}$, Chaofeng Shao ${ }^{2, \mathrm{~b}}$, Chenyang Xue $\mathrm{e}^{3, \mathrm{c}}$ \\ ${ }^{1}$ College of environmental science and engineering, Nankai University, Tianjin, China \\ ${ }^{2}$ College of environmental science and engineering, Nankai University, Tianjin, China \\ ${ }^{3}$ College of environmental science and engineering, Nankai University, Tianjin, China \\ imyxy330@163.con, ${ }^{b}$ shaochaofeng@163.com, ${ }^{c}$ 1661374517@qq.com
}

\begin{abstract}
Keywords: fertilizer and pesticide application, statistical analysis, efficiency
Abstract. The problem of excessive use of pesticide and chemical fertilizer in China has received attention in recent years. Based on statistical data, the comparative analysis of the application rates of fertilizer and pesticide were carried out between China and typical developed countries, to illustrate the problems of fertilizer and pesticide application faced in China. The results showed:1) compared with the typical developed countries (Japan, The UK, The U.S.A, France and Germany)in the world, China has the highest fertilizer consumption and fertilizer application rates but the lowest output rates of fertilizer.2)The pesticide consumption in China ranks first among these typical developed countries, the pesticide application rates is the second(after Japan),and the output rates of pesticide is the last. 3)Under the background of economic transformation and ecological civilization construction, there is a long way to go to promote the efficient fertilization and green disease and pest control in the future.
\end{abstract}

\section{Introduction}

Fertilizers and pesticides are input that is critical to agriculture, forestry, public health and the domestic sphere. Fertilizers are used to promote soil fertility and pesticides are used to suppress plant and animal pests such as weeds, insects, and plant pathogens, while reducing the amount of labor, fuel, and machinery used for pest control. These benefits translate into lower production costs, higher cereals yield and/or quality, less vector disease and increased profits in agriculture, forestry, public health and the domestic sphere. However, the benefits of fertilizer and pesticide use are accompanied by potential risks to both the natural environment and human and animal health. Research shows that the introduction and release of large amounts of reactive nitrogen along with the intensive fertilizer application has a series of undesirable impacts on ecosystems, including ozone-induced injury to crops and forests, soil salinity, heavy metal accumulation over enrichment of aquatic ecosystems, biodiversity losses, visibility-impairing haze, and global climate change [1,2]. And the abuse of pesticides leads to loss of biodiversity due to that the impact of pesticides consists of the effects of pesticides on non-target plants and animals. Pesticides which are not easily degradable will persist in soil, leach to groundwater and surface water, enter the organism, bioaccumulate in food chains and consequently influence also human health [3].

In this context, many countries have been developing political measures which are a mixture of regulations, technical means and economic measure to mitigate those agro-environmental issues caused by the irrational use of fertilizers and pesticides. For example, In Japan, it was in the New Policy for Food, Agriculture and Rural Areas (New Policy) issued by the Ministry of Agriculture, Forestry and Fisheries (MAFF) in 1992 that consideration for environment was formally addressed in agricultural policy as one of the main policy objectives for the first time. Subsequently, eco-friendly agriculture was written as policy target in the New Basic Act in 1999, and in addition, the so-called Three Laws on Agro-environment (i.e., the Act on Promotion of Introduction of Sustainable Agricultural Production Practices, Revised Fertilizers regulation Act and Act on the Appropriate Treatment and Promotion of Utilization of Livestock Manure, and Introductions of economic 
measures such as direct payments to farmers) were established to diminish the environmental loads caused by agriculture[4]. And in America, the authorities together with famers are trying to set up procedures of "best management practices" for fertilization to minimize damage to the environment, taking considering the economic needs of famers and the ability of fertilizer manufacturers to comply with regulations. Meanwhile, Acts, such as Federal Insecticide Fungicide and Rodenticide Act and the Federal Food, Drug, and Cosmetic Act(FFDCA) have been adopted by the authorities to regulate pesticides and pesticide residues [5]. They have also launched some government programs to encourage the development and use of biological and cultural methods, which include area wide pest management, integrated pest management (IPM) [6,7], national organic standards, and regulatory streamlining for biological pest control agents. In the 12th five-year plan of the National economic and social development in China, Consideration for the control of non-point source agriculture pollution was written as a crucial task. China has also developed polices, for example through the implement of The Campaign on Zero Growth of Fertilizer and Pesticide Consumption by 2020 to deal with those problems related to the rampant use of these chemicals. Nevertheless, comparing with developed countries, it is a long way to go to promote the efficient fertilization and green disease and pest control in the future.

Accordingly, this paper aims to reveal the problems in fertilizer and pesticide application in China through comparative analysis of their total consumption and application efficiency with the typical developed countries, and to provide recommendation toward solving these problems.

\section{The Fertilizer use and Pesticide Use in China}

\section{An Overview of Fertilizer Use in China}

Figure.1 shows the fertilizer consumption and fertilizer application rates(kilograms per hectare of arable land) in China from 1996 to 2015.With the rapid development of agricultural production, The fertilizer consumption in China has increased from $3827.9 \times 10^{4}$ tons to $6022.6 \times 10^{4}$ tons with an annual average growth rate of $2.3 \%$; The fertilizer application rates (measured with kilograms per hectare of arable land) in China has raised by 446.1 kilograms per hectare of arable land with an annual average growth rate of $2.6 \%$. China has launched the project of formula fertilization with soil test since 2005 , and through the implementation of this project, the average annual growth rates of fertilizer consumption in 2006-2015 has reduced by 2\% compared with that of rates in 1996-2005. Simultaneously, the average annual growth rates of fertilizer application rates have decreased by $2.1 \%$ as well. Accordingly, the average annual growth rate of fertilizer application in China is close to the growth rate of fertilizer consumption, indicating that the increase of fertilizer consumption in China is mainly due to the growth of fertilizer application rates.

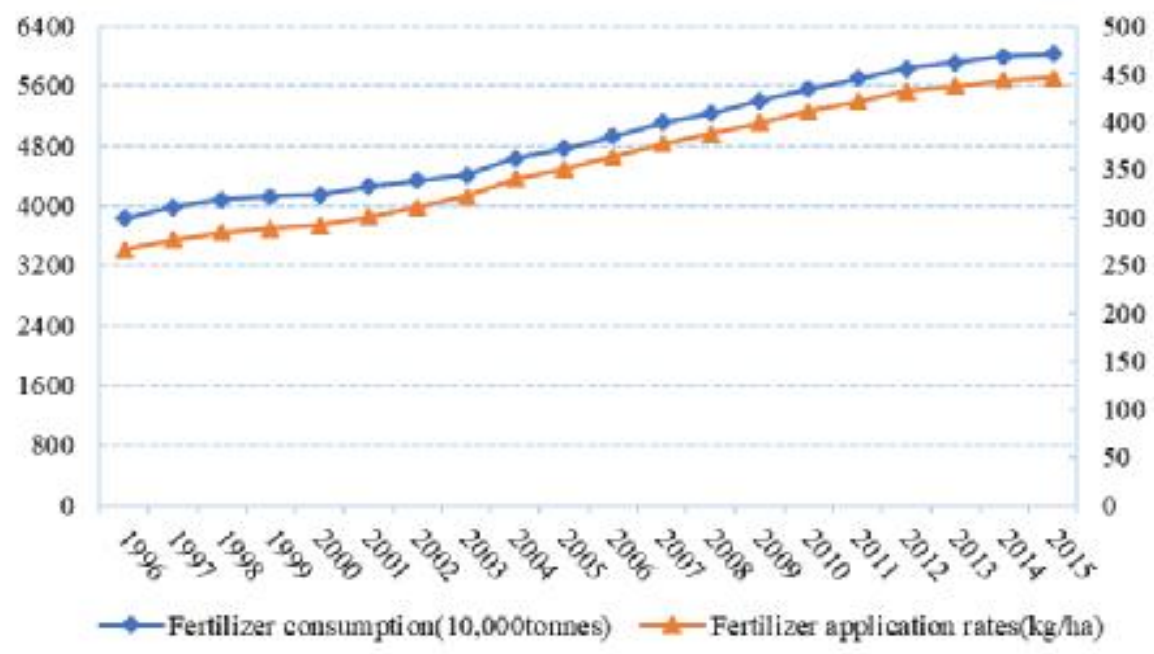

Figure. 1 the Fertilizer Consumption and Fertilizer application rates in China from 1996-2015 Data source: China agriculture statistical report1996-2015[8] 
An Overview of Pesticide Use in China

The pesticides consumption in China has shown a rapid upward trend since 1996(Figure 2). The total consumption of pesticides in China was $114.1 \times 10^{4}$ tons in 1996 , which rapidly increased to $178.3 \times 10^{4}$ tons in 2015. At the same time, the pesticide application rates (Average use per area of cropland, $\mathrm{kg} / \mathrm{ha}$ ) was increasing. According to the sown area of crops, the growth rate of pesticides' consumption is much faster than the growth rate of crops' sown area, which is 6.5 times faster than sowing area of crops. From 1996 to 2015, the sown area of crops has increased from 152,300 hectares to 166,000 hectares with an average annual growth rate of $0.4 \%$, while the pesticide application rates in China has increased from $7.9 \mathrm{~kg} / \mathrm{ha}$ to $12.2 \mathrm{~kg} / \mathrm{ha}$ with an average annual growth rate of $2.6 \%$ at the same period.

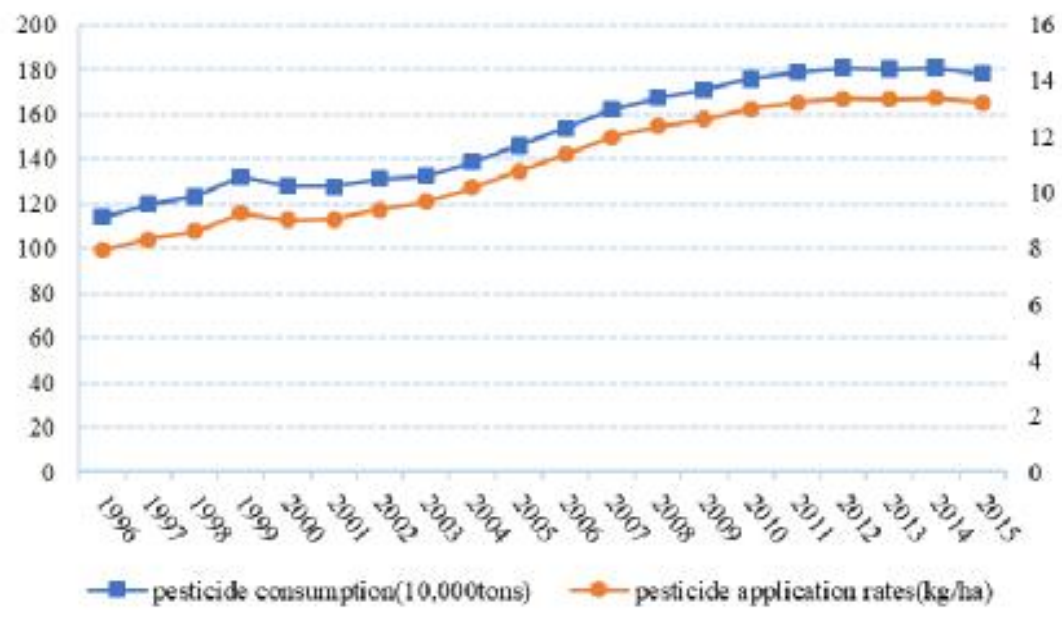

Figure. 2 the Pesticide Consumption and Pesticide application rates in China from 1996-2015 Data source: China agriculture statistical report1996-2015[8]

\section{An Comparison Analysis of Fertilizer Application Rates between China and Typical developed countries}

An Comparison of Fertilizer Consumption

The fertilizer consumption in China has increased form $10.12 \times 10^{6}$ tonnes in 1961 to $51.12 \times 10^{7}$ tonnes in 2015 with an annual average growth rate of $7 \%$, which is twice as much as the average growth rate of the world(3\%) according to the IFA Dataset. And the China's share of the world fertilizer consumption has also raised from 3\% to 27\% during 1961-2015(Figure.3). Apparently, China has been the main engine of global fertilizer demand growth in past decades.

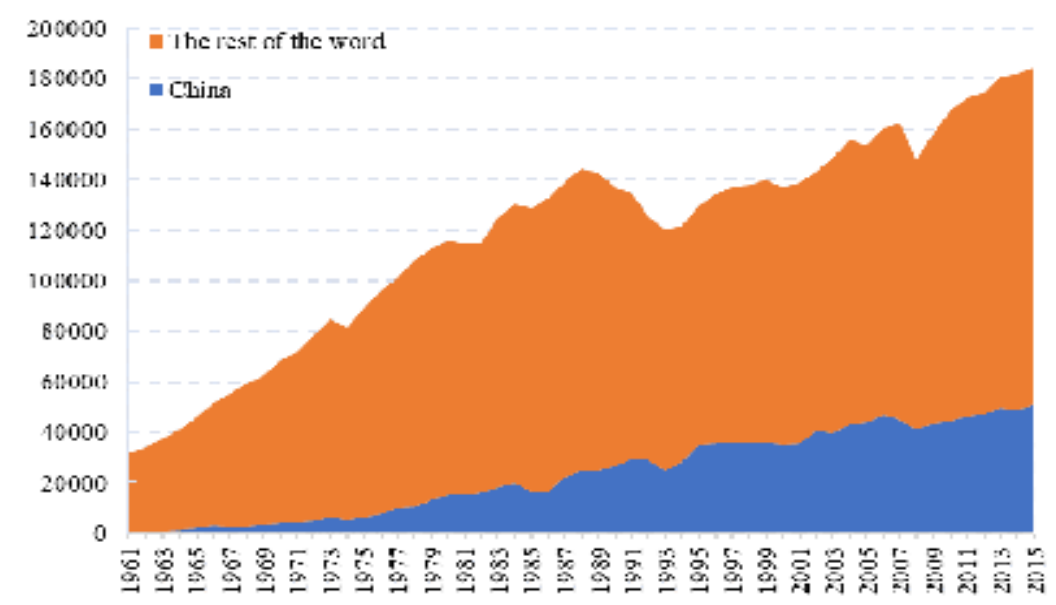

Figure.3 Fertilizer Consumption of China and the Rest of World

Data source: the IFA(international fertilizater association) Datasets[9] 
Compared with the typical developed countries (Japan, The UK, The U.S.A, France and Germany)in the world, China has the highest fertilizer consumption since the 1987 (Figure.3).Moreover, different from with the increasing situation of the quantities of using fertilizers in China, in the U.S.A, the fertilizers consumption has been cutting down, keeping $18 \sim 22$ million tonnes and increasing 1.8\% every year;In the France and the UK, the usage of fertilizers has been decreasing, in Japan and Germany, there has been negative growth, climbing $-0.6 \%$ and $-0.9 \%$ respectively.

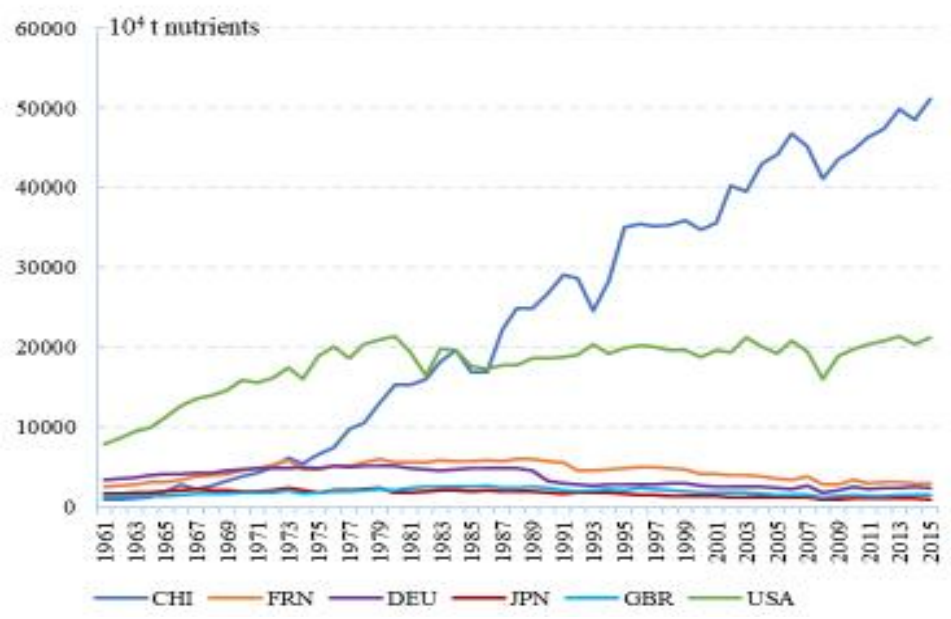

Figure.4The Development Trend of Fertilizers Consumption

Data source: the IFA(international fertilizater association) Datasets[9]

An Comparison of Fertilizer Application Rates

China's fertilizer application rates (kilograms per hectare of arable land) has increased from $377.5 \mathrm{~kg} / \mathrm{ha}$ in 2002 to $506.1 \mathrm{~kg} / \mathrm{ha}$ in 2015 , with an average annual growth of $2.1 \%$, which exceeded the internationally recognized $15 \mathrm{~kg} / \mathrm{ha}$ fertilization limit (Table.1). The fertilizer application rates in China are generally higher than that of other countries indeed.

Table.1 Fertilizer application rates [kg/ha] in China and Typical Developed Countries

\begin{tabular}{cccccccc}
\hline Year & China & Japan & $\begin{array}{c}\text { United } \\
\text { Kingdom }\end{array}$ & $\begin{array}{c}\text { United } \\
\text { States }\end{array}$ & France & Germany & World \\
\hline 2002 & 377.5 & 333.5 & 319.1 & 112.5 & 211.3 & 220.1 & 106.4 \\
2003 & 394.0 & 335.2 & 314.2 & 119.6 & 223.4 & 219.7 & 111.4 \\
2004 & 413.7 & 353.7 & 287.3 & 122.7 & 212.1 & 215.1 & 114.8 \\
2005 & 423.4 & 348.0 & 272.8 & 118.6 & 192.5 & 208.8 & 114.1 \\
2006 & 452.0 & 332.8 & 254.2 & 126.2 & 190.4 & 194.4 & 117.8 \\
2007 & 469.4 & 350.5 & 254.1 & 123.3 & 209.3 & 221.9 & 124.4 \\
2008 & 482.9 & 278.2 & 208.2 & 112.4 & 152.4 & 159.6 & 120.1 \\
2009 & 498.9 & 238.9 & 239.9 & 108.5 & 120.6 & 181.4 & 119.6 \\
2010 & 515.4 & 259.8 & 251.9 & 117.1 & 150.5 & 211.6 & 128.2 \\
2011 & 533.4 & 263.9 & 73.7 & 132.3 & 141.3 & 191.5 & 133.0 \\
2012 & 551.0 & 247.2 & 235.0 & 132.6 & 160.8 & 198.9 & 135.0 \\
2013 & 559.0 & 244.7 & 246.6 & 138.1 & 172.2 & 203.5 & 137.9 \\
2014 & 567.3 & 245.7 & 243.4 & 135.6 & 171.8 & 217.7 & 140.8 \\
2015 & 506.1 & 222.8 & 246.9 & 136.0 & 168.7 & 202.2 & 138.9 \\
\hline
\end{tabular}

Data source: FAO Datasets[10]

FAO data shows that China has consumed 481.7 kilograms fertilizers per hectare of arable land per year, which is 3.1 times of the world's annual fertilizer application rates during 2002-2015(Figure.4). And Compared with different developed countries in Asia, Europe and America, China's fertilizer application rates (kilograms per hectare of arable land) is the highest. 


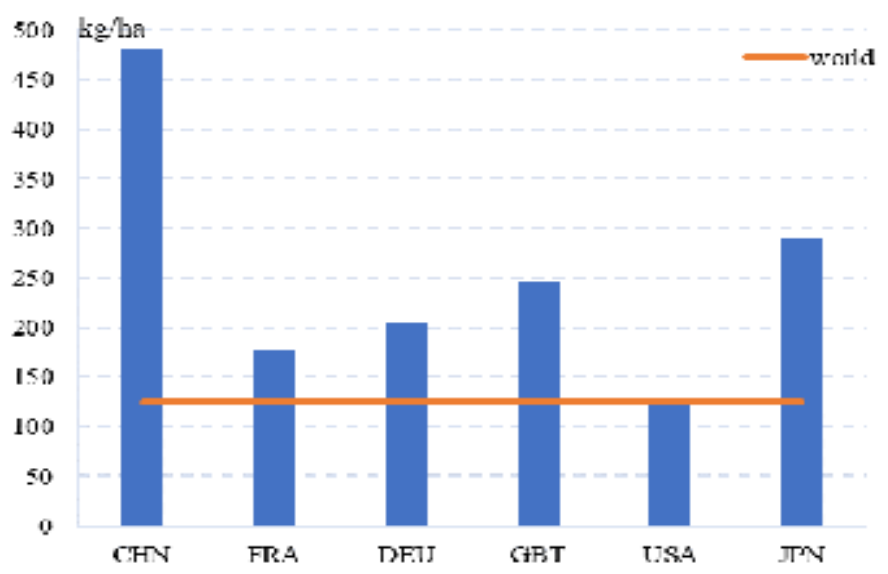

Figure.5 Annual average fertilizer application rates in China and Typical developed Countries Data source: FAO Datasets[10]

An Comparison of the Pesticide's output rates

Concerning the effect of fertilizer, the output rate of fertilizer (cereals yield per kilograms of fertilizer ) will be counted according to the FAO Data (Figure.5), from 2002 to 2014, China's fertilizer output rate is on the decline, which has reduced from $12.9 \mathrm{~kg} / \mathrm{kg}$ to $10.4 \mathrm{~kg} / \mathrm{kg}$, while other typical developed countries like the United Kingdom, the United States, Japan, France and Germany has increased $42.6 \%, 12.6 \%, 38.5 \%, 42.6 \%$ and $30.2 \%$ respectively. In general, the fertilizer output rate of China is far below the level of that of developed countries, and lower than the average rates of the world.

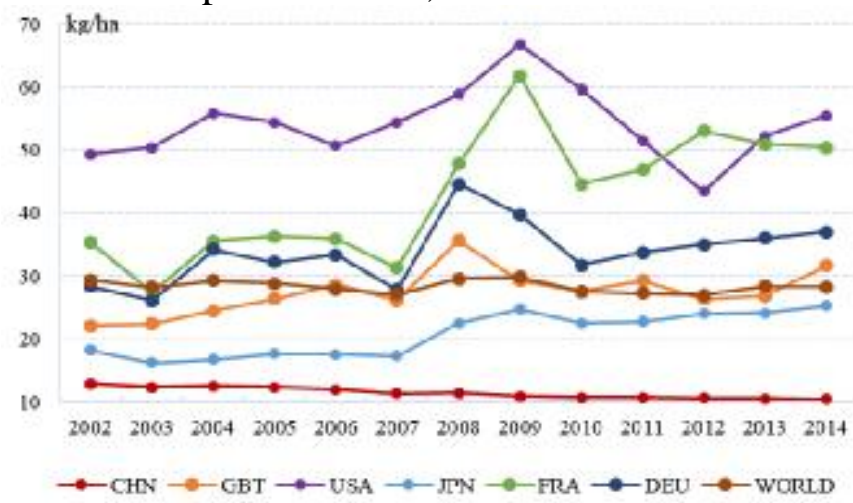

Figure.6 Fertilizer Output Rate in China and Typical Developed Countries in 2002-2014 Data source: FAO Datasets[10]

\section{An Comparison Analysis of Pesticide Application Rates between China and Typical developed countries}

An Comparison of Pesticide Consumption

Compared with the typical developed countries (Japan, The UK, The U.S.A, France and Germany)in the world, China's pesticide consumption is the highest.In 1996, the domestic pesticide consumption was $11.4 \times 10^{4}$ tons, then this number has mushroomed to $18.07 \times 10^{4}$ tons rapidlly in 2014 with an annual average growth rate of $2.5 \%$,which is the highest among these countries.Morever, there has been a general uptrend in China's pesicide consumption during 1996 2014, while the pesticide consumption in typical developed contries has showed a decrease tendency(Figure.6).Different from with the increasing situation of the pesticide consumption in China, in the Germany, the pesticide consumption has been cutting down, increasing $2.0 \%$ every year;In the U.S.A, France, the UK and the Japan, there has been negative growth, climbing $-0.7 \%,-1.3 \%,-3.0 \%$ and $2.8 \%$ respectively. 


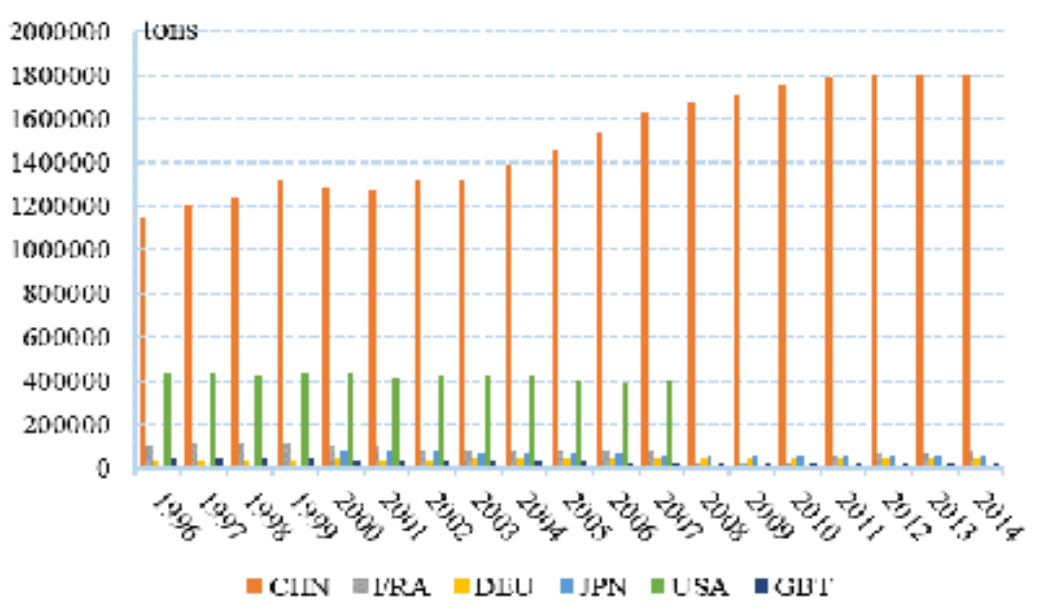

Figure.7 Pesticide Consuption in China and Typical developed Coutries in 1996-2004 Data source: FAO Datasets [10]

Table.2 Pesticide application rate(kg/ha) in China and Typical Developed Countries

\begin{tabular}{ccccccc}
\hline Year & China & Japan & $\begin{array}{c}\text { United } \\
\text { Kingdom }\end{array}$ & $\begin{array}{c}\text { United } \\
\text { States }\end{array}$ & France & Germany \\
\hline 1996 & 8.8 & NA & 5.8 & 2.4 & 5.1 & 2.6 \\
1997 & 9.2 & NA & 5.5 & 2.4 & 5.7 & 2.5 \\
1998 & 9.4 & NA & 5.6 & 2.4 & 5.5 & 2.8 \\
1999 & 10.2 & NA & 6.0 & 2.4 & 5.9 & 2.5 \\
2000 & 9.9 & NA & 5.6 & 2.4 & 5.0 & 2.9 \\
2001 & 10.0 & NA & 5.8 & 2.3 & 5.1 & 2.8 \\
2002 & 10.5 & 333.5 & 5.3 & 2.4 & 4.2 & 2.9 \\
2003 & 10.8 & 335.2 & 5.4 & 2.4 & 3.8 & 3.0 \\
2004 & 11.2 & 353.7 & 5.3 & 2.5 & 3.9 & 2.9 \\
2005 & 11.7 & 348.0 & 5.4 & 2.4 & 4.0 & 3.0 \\
2006 & 12.7 & 332.8 & 3.7 & 2.4 & 3.7 & 3.2 \\
2007 & 13.3 & 350.5 & 3.6 & 2.4 & 4.0 & 3.4 \\
2008 & 13.7 & 278.2 & 3.6 & NA & 1.4 & 3.6 \\
2009 & 14.0 & 238.9 & 3.5 & NA & 1.2 & 3.2 \\
2010 & 14.4 & 259.8 & 2.8 & NA & 1.2 & 3.4 \\
2011 & 14.7 & 263.9 & 2.7 & NA & 3.2 & 3.6 \\
2012 & 14.8 & 247.2 & 2.8 & NA & 3.3 & 3.8 \\
2013 & 14.8 & 244.7 & 2.8 & NA & 3.5 & 3.6 \\
2014 & 14.8 & 245.7 & 2.9 & NA & 3.9 & 3.8 \\
Annual average pesticide & & & & & & 3.0 \\
application rate & 12 & 13.4 & 4.4 & 2.4 & 4.1 & $2.0 \%$ \\
annual average growth & $2.8 \%$ & $-2.3 \%$ & $-3.5 \%$ & $0.1 \%$ & $-1.4 \%$ & \\
rate & & & & & & \\
\hline Dat & & & & & \\
\hline
\end{tabular}

Data source: FAO Datasets[10]

An Comparison of Pesticide Application Rates

The statistics about pesticide from 1996-2014 are gathered from FAO Dataset, and this can be demonstrated by comparing the China's pesticide application rate with typical developed countries, as seen in Table2.China's pesticide application rate (Average use per area of cropland) has increased from $8.79 \mathrm{~kg} / \mathrm{ha}$ in 1996 to $14.8 \mathrm{~kg} / \mathrm{ha}$ in 2014, with an average annual growth of $2.8 \%$, which ranked the first among these typical developed countries. And Compared to these developed countries, the pesticide application rate in China is second only to that rate in Japan, however, the pesticide 
application rate in China is three times as high as that rate in France and U.K, four time as high that rate in Germany, and five times as high as that rate in U.S.A.

An Comparison of the Pesticide's output rate

The output rate of pesticide (pesticide consumption per kilogram of cereals yield, $\mathrm{kg} / \mathrm{kg}$ ) were calculated based on the FAO Data (Figure.5), China's fertilizer output rate has presented a decrease trend in the past 19 years ,which has reduced from $556.5 \mathrm{~g} / \mathrm{kg}$ to $397.2 \mathrm{~kg} / \mathrm{kg}$, falling about 28.6 per cent, while other typical developed countries like the United Kingdom, the United States, Japan, France and Germany has increased $42.6 \%, 12.6 \%, 38.5 \%, 42.6 \%$ and $30.2 \%$ respectively. In general, the fertilizer output rate of China is below the level of that of developed countries and lower than the average rates of the world.

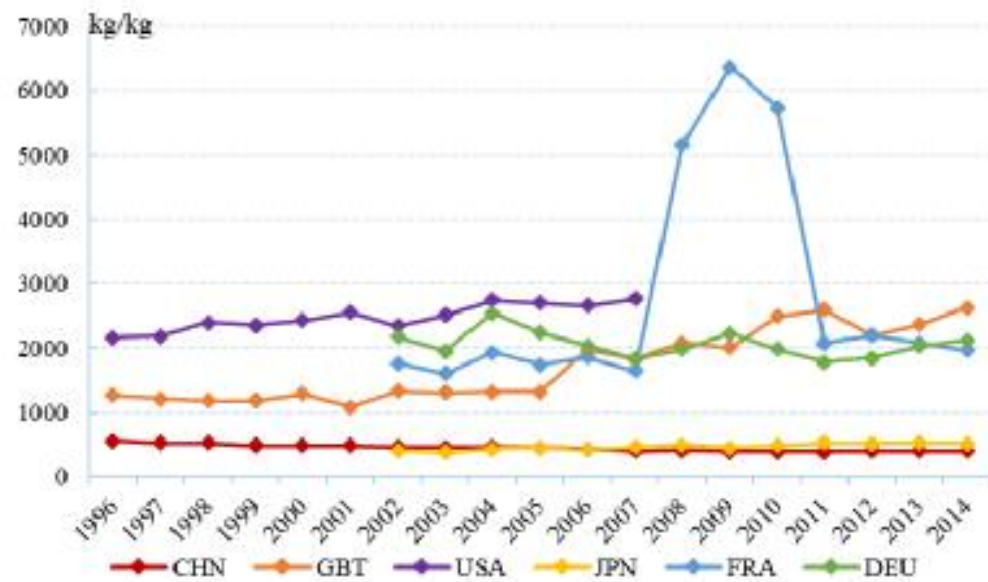

Figure.8 Pesticide Output Rate in China and Typical Developed Countries in 1996-2014

Data source: FAO Datasets[10]

\section{Conclusions}

Based on statistical data, a comparative analysis of the differences in fertilizer and pesticide application were carried out between China and the typical developed countries in the world from three perspectives: the total consumption of fertilizer and pesticide, the application rate (the intensity of application) and the output rate.

(1) The increase of the crop yields in China is mainly dependent on the intensive input of pesticides and fertilizers, resulting a series of environmental problems such as soil hardening, ozone-induced injury to crops and forests, over enrichment of aquatic ecosystems, biodiversity losses and so on. It is imminent to reduce chemical fertilizers and pesticides and improve the efficiency of chemical fertilizers and pesticides.

(2) The output rate of fertilizer and pesticide in China is generally lower than that of other typical developed countries, mainly in two aspects. Firstly, the fertilization technique and pesticide apply technology in China are relatively backward. To promote and popularize the formula fertilization with soil test, fertilizer deep placement, integrative water and fertilizer planting technology and biological pest management techniques, the authorities should draw lessons from those typical developed countries like the U.S.A and Japan. Secondly, considering the defect of the fertilizer and pesticide management system, the economic, effective and environmental-friendly techniques for the rational and effective use of pesticide and fertilizer as well as the policy system are supposed to be developed and strengthened.

\section{Acknowledgements}


This work was financially supported by the National Research and Development Projects(NO.2016ZFD201201), "Assessment of Environmental Effects of the Reduction and Efficient Use of Pesticide and Fertilizer".

\section{References}

[1] Ilic, Ivana, B. Krstic, and S. Jovanovic: Environmental performances of agriculture in the European Union countries. 64.1(2017):41-55.

[2] Lamberth, C, et al: Current challenges and trends in the discovery of agrochemicals. Science,341.6147(2013):742-6.

[3] Aktar, M. W., D. Sengupta, and A. Chowdhury: Impact of pesticides use in agriculture: their benefits and hazards. Interdisciplinary Toxicology 2.1(2009):1.

[4] Evaluation of Agricultural Policy Reforms in Japan: (Complete Edition - ISBN 9789264061545).Sourceoecd Agriculture \& Food 4(2009):i-123.

[5] Osteen, Craig, J. Gottlieb, and U. Vasavada: Agricultural Resources and Environmental Indicators, 2012 Edition. Ssrn Electronic Journal 85.1(2012):págs. 29-32.

[6] Fernandezcornejo, Jorge, et al.: Pesticide Use in U.S. Agriculture: 21 Selected Crops, 1960-2008. Economic Information Bulletin (2015).

[7] Information on http://www.haifa-group.com

[8] Ministry of Agriculture, PRC: China agriculture statistical report. Beijing: China Agriculture Press; (2001-2007).

[9] Information on http://www.fao.org/faostat/en/

[10] Information on http://ifadata.fertilizer.org 